\title{
A atividade tradutória de obras da literatura infantil aplicada ao ensino de língua estrangeira
}

\section{Translational Activity Using Works of Children's Literature Applied to Foreign Language Teaching}

\author{
Valdecy de Oliveira Pontes* \\ Natália Sampaio Alencar Lima* \\ Simone Lopes Almeida Nunes ${ }^{* * *}$
}

Resumo: 0 uso da tradução já passou por diversas mudanças referentes ao ensino de língua estrangeira (LE), de elemento fundamental na abordagem Gramática-Tradução à sua exclusão por completo com a Abordagem Direta. Atualmente, ela volta lentamente a ganhar espaço em sala de aula. A tradução como ferramenta pedagógica, ou seja, quando o professor a utiliza para verificar e reforçar a aprendizagem, é de grande valia e, quando contextualizada com elementos socioculturais, torna-se mais significativa e eficaz, além de contribuir para formação da identidade cultural do indivíduo, bem como para o aprimoramento do conhecimento da língua materna. Dessa forma, propomos nesse artigo atividades tradutórias que utilizam por base dois clássicos da literatura mundial: Alice's Adventures in Wonderland (1865) e Le Avventure di Pinocchio (1883) com intuito de aproximar o aluno não apenas da língua, mas, também, da cultura da qual ela faz

\footnotetext{
* Professor do Departamento de Letras Estrangeiras e do Programa de Pós-Graduação em Estudos da Tradução da Universidade Federal do Ceará. valdecy.pontes@ufc.br

** Mestranda na Pós-Graduação em Estudos da Tradução (UFC)

*** Mestranda na Pós-Graduação em Estudos da Tradução (UFC)
} 
PONTES, V. O; LIMA, N. S. A.; NUNES, S. L. A. - A atividade tadutória de obras de literatura infantil aplicada ao ensino de língua estrangeira

parte. Para tanto, apoiar-nos-emos, principalmente, nas propostas de Balboni (2011), Romanelli (2009), Hurtado Albir (1998), Atkinson (1993). As atividades tradutórias serão realizadas com alunos da Graduação de Letras dos cursos de língua inglesa e língua italiana com níveis C1 a C2 (Quadro Europeu Comum de Referência para Línguas) em duas aulas de 1 hora e 30 minutos de duração. Em grupos, os estudantes traduzirão partes das obras originais e apresentariam suas versões em sala de aula, onde o professor seria encarregado de apresentar-lhes os elementos socioculturais ali existentes, além de uma ou mais versões da obra traduzida para o português para que lhes fossem mostrado como é possível haver várias leituras e traduções a partir de um único texto.

Palavras-chave: Alice; Pinocchio; cultura; ensino de língua estrangeira; tradução pedagógica.

Abstract: The use of translation in foreign language classes has come through many changes. From being the basis of the Grammar-Translation Approach to becoming completely absent in the Direct Approach, now it is slowly gaining acceptance again in the classroom. Translation as a teaching tool, in other words, when the teacher uses it to reinforce and check learning, is of great value and when contextualized with socio-cultural elements it becomes even more meaningful and effective. It also contributes to the formation of cultural identity as well as to the improvement of knowledge of the mother tongue. Thus, in this article we suggest using a translational activity based on two classics of world literature: Alice's Adventures in Wonderland (1865) and Le Avventure di Pinocchio (1883) in order to bring the student closer not only to the language, but also to the culture in which it is inserted. For this, it will be based on the proposals made by Balboni (2011), Romanelli (2009), Hurtado Albir (1998), Atkinson (1993). The translational activities are addressed to undergraduate students of English and Italian Language courses with levels C1 to C2 (Common European Framework of Reference for Languages) to be done in two classes with duration of 1 hour and 30 minutes. In groups, students translate parts of the original works and present their versions in the classroom where the teacher will present the socio-cultural elements underlying the texts, besides introducing to them one or more versions of the work translated into Portuguese showing the students how it is possible to have several readings and translations from a single text.

Keywords: Alice; Pinocchio; Culture; Foreign Language Teaching; Pedagogical Translation. 
PONTES, V. O; LIMA, N. S. A.; NUNES, S. L. A. - A atividade tadutória de obras de literatura infantil aplicada ao ensino de língua estrangeira

\section{Introdução}

O ensino de língua estrangeira, doravante LE, é algo bastante difundido no Brasil e no mundo, especialmente, nas últimas décadas, devido à formação de blocos econômicos que acarretam uma globalização mais acelerada e, consequentemente, uma maior interação entre indivíduos de culturas distintas. A linguagem constitui um elemento chave no conceito de cultura, como afirma Laraia (1986 apud HINOJOSA \& LIMA 2007: 2), havendo entre elas uma relação dialética, uma vez que a comunicação é um processo cultural que torna possível a existência da cultura como um complexo de conhecimentos, valores e costumes. Com os avanços dos Estudos Culturais, a sua abrangência interdisciplinar e a fluidez do que se considera cultura, inúmeros são os conceitos já desenvolvidos sobre a mesma. Para defini-la, tomaremos por base o conceito elaborado por Hall que a define como:

o terreno real, sólido, das práticas, representações, línguas e costumes de qualquer sociedade histórica específica, assim como as formas contraditórias de 'senso comum' que se enraizaram na vida popular e ajudaram a moldá-la (HALL 1986 apud SILVA 1995: 15).

A definição supracitada é bastante abrangente, não limitadora, lida com costumes populares assim também como com a língua como elementos formadores de um sistema maior, a cultura. Podemos perceber que vivemos imersos em cultura e não podemos nos dissociar da mesma, assim como não podemos separar uma língua da cultura a qual ela faz parte. Pretendemos aqui refletir sobre como a cultura pode se fazer presente através da língua e como leva-la à sala de aula de língua estrangeira. No presente artigo, trabalharemos com dois clássicos da literatura infantil: Le Avventure di Pinocchio (1883), de Carlo Collodi; e Alice's Adventures in Wonderland (1865), de Lewis Carroll e os aspectos culturais subjacentes como forma de 
PONTES, V. O; LIMA, N. S. A.; NUNES, S. L. A. - A atividade tadutória de obras de literatura infantil aplicada ao ensino de língua estrangeira

incentivar os alunos de LE a entrarem em contato direto com aspectos socioculturais intrínsecos à língua alvo. De acordo com Even-Zohar (1990: 2223) e sua teoria dos polissistemas:

[...] qualquer [...] (poli)sistema (como a língua ou a literatura) é um componente de um (poli)sistema maior - o da 'cultura' - [...] e, portanto, se correlaciona com essa totalidade e seus outros componentes.

O professor de LE deve ter em mente que seu papel em sala de aula está além do ensino de vocabulário e de estruturas gramaticais da língua. Unindo os pensamentos de Fleuri (2003 apud HINOJOSA \& LIMA 2007: 3) ao afirmar que a interculturalidade é uma forma de superar as barreiras culturais que separa o "outro" e Walesko (2006 apud HinojosA \& LIMA 2007: 4) que propõe a formação de uma identidade cultural heterogênea e sem preconceitos através do contato com outras culturas, podemos dizer que o docente deve incitar o aluno a ir além dos horizontes de sua própria cultura e colocá-lo frente a frente com a cultura do "outro" para que as barreiras sejam transpostas havendo assim uma multiplicidade cultural e social que o faça questionar a sua própria cultura resultando em uma formação de identidade rica e heterogenia, livre de preconceitos culturais e etnocentrismo, mas ao mesmo tempo fortalecendo os laços com sua própria cultura, nunca negligenciando-a.

Um recurso significativo para estreitar os laços culturais entre línguas é o uso do texto literário como atividade de tradução. É comum encontrarmos atividades com textos literários nos livros didáticos destinados ao ensino de LE, mas, dificilmente, deparamo-nos com a atividade tradutória ligada a esses textos. Tais textos podem abrir diversas possibilidades de atividades pela riqueza das suas contribuições seja no aspecto linguístico, histórico, cultural, social, político, para citar algumas. 
PONTES, V. O; LIMA, N. S. A.; NUNES, S. L. A. - A atividade tadutória de obras de literatura infantil aplicada ao ensino de língua estrangeira

Escolhemos trabalhar com clássicos da literatura infantil porque acreditamos que a literatura infantil pode ser um caminho para a crítica social velada e para dar voz às minorias oprimidas. Pois, a literatura adulta passa a ser alvo de maior observação por parte dos repressores. Esse fato contribui para que, ao lado de uma literatura massificada, surja outra, mais crítica, que demonstre as diferenças presentes na sociedade. Contos de fadas tradicionais passam a ser usados como metáfora da vida social, política e econômica. Nas obras Le avventure di Pinocchio e Alice's Adventures in Wonderland, são apresentados momentos em que a pobreza, a desigualdade e o autoritarismo são os pontos principais, críticas da época que persistem até hoje.

Na segunda seção do presente artigo, refletiremos acerca da relevância da atividade tradutória nas aulas de Língua Estrangeira tendo por base a mudança do papel da tradução em sala de aula, anteriormente rejeitada, passando, a seguir, por um lento processo de aceitação e inclusão. Em seguida, apresentaremos propostas de atividades tradutórias, contextualizando-as e discutindo os aspectos culturais que podem ser pontuados nas obras literárias. Dessa forma, dedicaremos a terceira seção à obra Alice's Adventures in Wonderland e a quarta, à obra Le avventure di Pinocchio.

\section{A atividade tradutória em sala de aula de língua estrangeira}

Quando nos referimos ao uso da tradução em sala de aula de língua estrangeira, devemos estar cientes do longo caminho percorrido pela mesma: 
PONTES, V. O; LIMA, N. S. A.; NUNES, S. L. A. - A atividade tadutória de obras de literatura infantil aplicada ao ensino de língua estrangeira

do pilar da Abordagem ${ }^{1}$ Gramática-Tradução, passa a completa exclusão com a Abordagem Direta. Atualmente, a tradução vem reconquistando seu espaço lentamente no ensino de LE. A tradução como ferramenta pedagógica, ou seja, quando o professor a utiliza para verificar e reforçar a aprendizagem, é de grande valia e, quando contextualizada com elementos socioculturais, torna-se mais significativa e eficaz, além de contribuir para formação da identidade cultural do indivíduo, bem como para o aprimoramento do conhecimento da língua materna. Como afirma Hurtado Albir (1998, apud LUCINDO 2006: 3) a tradução vai além do processo de transferência de palavras, ela é um "processo de reexpressão do sentido que as palavras e frases adquirem no contexto" e para que ela seja considerada de qualidade, é necessário levar em conta o

sentido produzido a partir da confluência dos elementos linguísticos e extralinguísticos (conhecimento da situação, do tema, dos códigos sócio-culturais, etc.) que intervêm na comunicação. (HURTADO ALBIR 1998, apud LUCINDO 2006: 3).

Ainda, segundo a autora, a tradução pode ser classificada como interiorizada ou pedagógica. Aquela é feita por todo aprendiz de LE, principalmente, nos estágios iniciais, pois tudo que o aprendiz constrói ou destrói se baseia no seu conhecimento da Língua Materna (LM). Já a última, acontece em salas de aula como instrumento didático e se define pela utilização de exercícios escolares que visam à aquisição de uma LE. Romanelli (2009: 215), também, considera a tradução como vantajosa quando utilizada para discutir assuntos interculturais, dessa forma, pretendemos elaborar atividades tradutórias pedagógicas com intuito de levar o conhecimento

\footnotetext{
${ }^{1}$ A abordagem comunicativa surge no início dos anos 80 , como novo método no ensino de LE, interferindo de forma positiva no papel da tradução em sala de aula - atividade anteriormente negligenciada -, pois volta-se a considerar a questão do discurso e da apropriação, já que a ideia central é a de que o aluno aprende na prática, como um parceiro ativo no processo de aprendizagem.
} 
PONTES, V. O; LIMA, N. S. A.; NUNES, S. L. A. - A atividade tadutória de obras de literatura infantil aplicada ao ensino de língua estrangeira

intercultural para dentro da sala de aula de LE para que o aluno fique mais próximo não apenas da língua, mas, também, da cultura que a constitui, tendo por base o conceito criado por Hall, citado anteriormente.

Novas atitudes, novas práticas podem direcionar o ensino de LE para uma transdisciplinaridade, uma interculturalidade que possibilita ao discente adquirir, além de um conhecimento linguístico, um enriquecimento na percepção de novas culturas, num processo interpessoal que surge no conhecimento do outro, do estrangeiro para, consequentemente, perceber a própria cultura.

Esse movimento que se dá ao ir ao encontro do outro para o conhecimento do próprio, ideias já defendidas pela teoria clássica da tradução como Schleiermacher (1813), é uma das contribuições do uso de atividades de tradução como instrumento didático no ensino de LE. É muito comum o uso do texto literário nos manuais de ensino de LE, principalmente em níveis mais avançados, e torna-se ainda mais relevante quando se utiliza a tradução nessa proposta pedagógica. Diante de tantas possibilidades que se nos apresentam, decidimos desenvolver essa proposta de atividade com duas obras da literatura infantil, pois acreditamos que as obras literárias que fazem referência à infância, ao imaginário, ao fantástico são obras de fácil identificação, portanto, podem incitar o interesse do aluno tanto para a leitura quanto para a atividade de tradução. 0 que não descarta o uso de outras obras do acervo da literatura.

Seguindo os parâmetros apresentados por Balboni (2011: 4-6) na utilização da tradução como técnica para o ensino de línguas, preocupamonos com a aceitabilidade da obra a ser trabalhada, para não causar desmotivação por parte dos alunos. Trabalhar com uma obra de mais de um século, pode até causar assombro nos alunos, mas é importante deixar claro, 
PONTES, V. O; LIMA, N. S. A.; NUNES, S. L. A. - A atividade tadutória de obras de literatura infantil aplicada ao ensino de língua estrangeira

para trabalhar esse filtro afetivo² (BALBONI 2011: 4), que se trata de uma literatura que foi escrita, inicialmente, como folhetim e, mesmo quando transformada em livro, nota-se que a oralidade está muito presente, ou seja, a obra de Collodi é simples e de fácil leitura, por isso o trabalho de tradução não será tarefa frustrante, mas frutuosa. Tratando-se de Alice, sabemos que é uma obra de possibilidades inesgotáveis de tradução, dependendo do público receptor escolhido, se infantil ou adulto, portanto, isso dará aos alunos a oportunidade de diversas versões enriquecendo, assim, o conhecimento da prática tradutória.

Os alunos, antes de começarem a atividade efetiva, podem ser apresentados ainda à pertinência - outro parâmetro individuado por Balboni (2011) - da obra para que a tradução não pareça uma atividade sem um fim específico. É interessante mostrar ao aluno que se está trabalhando com uma obra relevante no cenário político, social e econômico da Itália do século XIX:

A história de Pinóquio foi escrita no período da Restauração da Itália, ou seja, do recém-formado Reino da Itália, que congregava regiões com grandes diferenças históricas, de ordem política, administrativa, social, civil e linguística. Collodi, porém, escreve para as crianças sem se ater às regras moralístico-religiosas da época. A infância é um tema central na sua obra, tanto nos livros escolares como nos de ficção. Os críticos costumam distinguir em sua obra duas interpretações da infância: a histórica, diferenciada por classes sociais, e a simbólica (GUERINI 2009 apud MARQUES 2011: 91-92).

A mesma ideia pode ser aplicada em Alice's Adventures in Wonderland. Tendo sido escrito na era vitoriana, a obra é cheia de símbolos políticos,

\footnotetext{
${ }^{2}$ Para Krashen $(1987 ; 1988)$, o filtro afetivo parte do processo interno no qual configuram os estados emocionais, as atitudes, as necessidades, a motivação do aprendiz ao aprender uma língua, e que regula e seleciona modelos de língua a serem aprendidos, a ordem de prioridade e a velocidade nesta aquisição.
} 
PONTES, V. O; LIMA, N. S. A.; NUNES, S. L. A. - A atividade tadutória de obras de literatura infantil aplicada ao ensino de língua estrangeira

críticas e, disfarçado pelo seu nonsense, vai de encontro ao moralismo da época, como afirma Martin Gardner em Annotated Alice:

0 fato é que o nonsense de Carroll está longe de ser tão aleatório e despropositado quanto parece a uma criança americana de nossos dias que tenta ler os livros de Alice (GARDNER 2002: vii).

Em ambas as atividades, serão escolhidos dois capítulos de cada obra para a atividade de tradução em sala de aula, tendo em vista que são duas obras longas para serem usadas com tal objetivo, o que tornaria a atividade cansativa e demorada. Balboni (2011: 1) alerta que a tradução só é uma atividade motivadora se o texto for motivador, a escolha de abreviar o texto literário é concernente à preocupação de apresentar uma atividade que seja, igualmente, estimulante. Pensamos trabalhar a tradução de partes das obras em sala de aula, mas, também, fora dela já que a atividade tradutória requer muita atenção, concentração e demanda tempo.

Tal atividade é destinada a alunos de língua italiana (Le avventure di Pinocchio) e língua inglesa (Alice's Adventures in Wonderland), do curso de graduação em Letras, entre os níveis $\mathrm{C} 1$ a $\mathrm{C} 2$, porque iremos trabalhar com textos originais, com particularidades linguísticas do século XIX, que requerem maior nível de conhecimento da língua. Segundo Kramsch:

o termo 'autêntico' é usado em oposição à linguagem artificial préfabricada dos livros-texto e dos diálogos instrucionais; refere-se à forma não-pedagógica de uso da linguagem em situação natural de comunicação (KRAMSCH 1993: 175).

Acreditamos que o uso de textos autênticos é relevante para o ensino de LE, uma vez que os discentes não trabalharão com textos voltados apenas para aspectos linguísticos específicos, comumente apresentados nos livros didáticos do ensino de LE. Especialmente se as obras escolhidas forem de 
PONTES, V. O; LIMA, N. S. A.; NUNES, S. L. A. - A atividade tadutória de obras de literatura infantil aplicada ao ensino de língua estrangeira

conhecimento geral em diversas culturas, a aprendizagem poderá ser mais significativa.

Tomaremos por base uma turma de língua italiana ou língua inglesa de ensino superior da Graduação de Letras composta de doze ou dezesseis alunos, em que quatro grupos seriam divididos sendo formados por três ou quatro estudantes. As atividades seriam trabalhadas em duas aulas com duração de 1 hora e 30 minutos. Ressaltamos que o momento em sala de aula será utilizado para discussão da produção e elucidação dos elementos culturais e não para a realização da atividade tradutória.

Os capítulos, selecionados pelos professores das respectivas línguas, seriam lidos por inteiro e por todos os alunos para que a explanação e discussão fossem entendidas por todos em sala de aula, porém cada parte seria designada a um grupo específico que ficaria encarregado de traduzi-la em casa e levar suas produções para sala de aula para o momento da apresentação oral fazendo uma síntese do que foi lido e apresentando exemplos comparativos da tradução feita com o original. 0 professor seria encarregado de fazer a elucidação dos elementos socioculturais e políticos presentes ao final da apresentação do grupo. Seria de grande valia, também, se o professor levasse uma edição já traduzida do livro, ou até mais de uma, para que, ao final, pudesse ser feita uma comparação das diferentes versões. Dessa forma, unimos duas propostas elaboradas por Atkinson (1993 apud ROMANELLI 2009: 217-218) para a prática da tradução no ensino de LE: corrigir uma tradução errada; consolidar mediante traduções; comparar versões diferentes (dadas pelo professor); comparar versões diferentes (escritas pelos estudantes); resumir uma tradução; e interpretar em sala de aula. Lembramos que o objetivo aqui não é que o professor trabalhe como juiz, mas que os alunos possam ter uma visão de como funciona a tradução e de que existem várias formas de executá-las (BALBONI 2011: 16). Apresentaremos, a seguir, uma breve contextualização das obras que servirão de base para as atividades 
PONTES, V. O; LIMA, N. S. A.; NUNES, S. L. A. - A atividade tadutória de obras de literatura infantil aplicada ao ensino de língua estrangeira

tradutórias propostas no presente artigo, iniciando com Alice's Adventures in Wonderland.

\section{Alice's Adventures in Wonderland}

Alice's Adventures in Wonderland, de Charles Lutwidge Dodgson, mais conhecido por seu pseudônimo Lewis Carroll, é considerada como clássico da literatura inglesa e uma das obras mais conhecidas e analisadas dentro do gênero literário nonsense. É sabido que uma das meninas por quem Carroll tinha maior sentimento de admiração era Alice Liddell que the implorou por uma estória durante um passeio que fizeram em 1862 e ele narrou o que seria o esboço de Alice's Adventures in Wonderland, que seria entregue à mesma, alguns anos depois como manuscrito ilustrado.

Tendo sido publicado em 1865, o livro foi primeiramente considerado como literatura infantil e posteriormente viu-se que se adequaria também à leitura adulta como afirma Sebastião Uchoa Leite:

Que os dois livros mais celebrados de Carroll, Alice in Wonderland e Through the Looking-glass, sejam livros para crianças, é verdade muito relativa. Na época, talvez. Hoje, mais de um século depois que foram publicados, são cada vez mais leituras para adultos. (LEITE 1980: 7).

A obra narra a história de uma menina chamada Alice e suas aventuras vividas em um mundo de fantasias. Por este ponto de vista, pode-se dizer que é mesmo um livro puramente infantil, mas o que o torna adequado a outras faixas etárias é a complexidade encontrada em sua escrita e a crítica social e política por trás de personagens inofensivos como coelhos apressados, ratos falantes e um exército de cartas de baralho. Carroll faz alusões à estrutura 
PONTES, V. O; LIMA, N. S. A.; NUNES, S. L. A. - A atividade tadutória de obras de literatura infantil aplicada ao ensino de língua estrangeira

social da época, além da reprodução de uma série de aspectos intrínsecos à cultura inglesa e à época vitoriana. Dessa forma, acreditamos ser um livro rico e amplamente conhecido para ser utilizado em uma atividade tradutória que visa apresentar a brasileiros os elementos pertinentes à cultura inglesa da época em que foi escrito e que seria adequado a qualquer faixa etária. Acreditamos ser pertinente o uso de um clássico da literatura em sala de aula, uma vez que esses podem passar despercebidos aos olhos dos leitores atuais e por ser uma obra de amplo conhecimento geral, um texto autêntico que pode despertar maior interesse nos alunos tornando, assim, a aprendizagem mais significativa.

\subsection{Atividade tradutória utilizando Alice's Adventures in Wonderland}

A atividade será realizada com alunos da Graduação do curso de Letras Inglês, tendo em média 12 a 16 integrantes com nível de proficiência $\mathrm{C} 1$ a C2, utilizando duas aulas com 1h30min de duração. Temos como objetivo apresentar aos alunos não somente a riqueza do texto original em inglês, mas, também, as várias formas de se traduzir a partir de uma mesma fonte, assim como desvendar os elementos socioculturais como costumes e expressões da era vitoriana que subjazem ao enredo.

Mantendo-nos em consonância com Hurtado Albir (1998) e a relevância da tradução em sala de aula como ferramenta pedagógica, com Balboni (2011) e a pertinência de se trabalhar um texto relevante que não cause frustração no aluno, sendo mediado pelo professor, e com Atkinson (1993) e as propostas de atividades tradutórias a serem utilizadas em sala de aula, faremos aqui a exemplificação da atividade tradutória utilizando este clássico da literatura inglesa. 
PONTES, V. O; LIMA, N. S. A.; NUNES, S. L. A. - A atividade tadutória de obras de literatura infantil aplicada ao ensino de língua estrangeira

Quadro 1 - Proposta de atividade 1

\begin{tabular}{|c|c|}
\hline Autor & Natália Sampaio Alencar Lima \\
\hline Tipo de atividade & Tradução de texto literário (literatura infantil) \\
\hline $\begin{array}{l}\text { Objetivos } \\
\text { linguísticos }\end{array}$ & $\begin{array}{l}\text { Perceber as diferenças linguísticas entre a } \\
\text { língua inglesa do século XIX e a língua inglesa } \\
\text { contemporânea, como expressões idiomáticas. }\end{array}$ \\
\hline Objetivos cognitivos & $\begin{array}{l}\text { Desenvolver a habilidade lexical a partir de } \\
\text { uma obra de literatura infantil permeada pelo } \\
\text { nonsense onde há animais e objetos falantes. }\end{array}$ \\
\hline $\begin{array}{l}\text { Objetivos } \\
\text { relacionais }\end{array}$ & $\begin{array}{l}\text { Desenvolver a capacidade de negociação e de } \\
\text { decisão compartilhada (atividade desenvolvida em } \\
\text { grupos). }\end{array}$ \\
\hline Nível linguístico & C1 ou C2 \\
\hline Tipo de língua & Segunda língua ou L2 \\
\hline Atividade adaptada & Estudantes universitários \\
\hline $\begin{array}{l}\text { Organização } \mathrm{da} \\
\text { atividade }\end{array}$ & Em grupos \\
\hline $\begin{array}{l}\text { Quando utilizar a } \\
\text { atividade }\end{array}$ & $\begin{array}{l}\text { Quando for oportuno. Pode ser muito útil } \\
\text { durante um laboratório de tradução para que se } \\
\text { compreenda a importância dos elementos culturais no } \\
\text { estudo da língua inglesa. }\end{array}$ \\
\hline Duração & Duas aulas de $1 \mathrm{~h}$ e $30 \mathrm{~min}$. \\
\hline $\begin{array}{l}\text { Materiais } \\
\text { necessários }\end{array}$ & Livro, caderno, dicionários e caneta. \\
\hline $\begin{array}{l}\text { Preparação } \\
\text { material }\end{array}$ & $\begin{array}{l}\text { Aquisição da obra literária ou reprodução dos } \\
\text { capítulos a serem utilizados na atividade. }\end{array}$ \\
\hline $\begin{array}{l}\text { Descriçãa } \\
\text { atividade }\end{array}$ & $\begin{array}{l}\text { 1. O professor separa a turma em } 4 \text { grupos com } \\
3 \text { ou } 4 \text { integrantes cada. } \\
\text { 2. Em seguida, apresenta a proposta de } \\
\text { atividade tradutória que será realizada, fala um pouco } \\
\text { sobre a relevância da obra literária escolhida e, } \\
\text { posteriormente, solicita que cada grupo inicie a } \\
\text { tradução dos capítulos } 6 \text { e } 7 \text { da obra Alice's } \\
\text { Adventures in Wonderland. A atividade tradutória será } \\
\text { iniciada em sala, com o auxílio do professor nesse } \\
\text { primeiro momento, e finalizada em casa. } \\
\text { 3. Na sala de aula, o professor ficará } \\
\text { observando e conduzindo a atividade, auxiliando em } \\
\text { eventuais dúvidas dos alunos. } \\
4 \text {. Na aula seguinte, uma vez que todos os } \\
\text { grupos tenham finalizado as suas traduções, } \\
\text { iniciaremos a discussão sobre o que gerou mais } \\
\text { dificuldade no processo tradutório ou, até mesmo, se } \\
\text { gerou alguma dificuldade. } \\
5 \text {. Ao fim das apresentações, o professor } \\
\text { elucida os elementos socioculturais e políticos } \\
\text { existentes ali, com a intenção de levar os alunos a }\end{array}$ \\
\hline
\end{tabular}


PONTES, V. O; LIMA, N. S. A.; NUNES, S. L. A. - A atividade tadutória de obras de literatura infantil aplicada ao ensino de língua estrangeira

\begin{tabular}{|l|l|}
\hline Outras sugestões & $\begin{array}{l}\text { refletirem que o processo tradutório não se restringe } \\
\text { aos elementos linguísticos, mas também aos culturais. }\end{array}$ \\
\hline $\begin{array}{l}\text { Seria de grande valia se o professor levasse } \\
\text { traduala de aula uma ou mais versões da obra } \\
\text { trada para o português para apresentar aos alunos } \\
\text { como é possível se fazer várias interpretações e } \\
\text { traduções a partir de um único texto e mostrando que } \\
\text { ele não está ali como juiz para julgar se a tradução foi } \\
\text { feita de forma correta ou não, mas como mediador da } \\
\text { atividade. }\end{array}$ \\
\hline
\end{tabular}

Sendo Alice's Adventures in Wonderland uma obra do gênero nonsense e não seguindo uma linearidade na narrativa e nem a constância dos personagens nos capítulos, salvo alguns como Alice dentre poucos outros, seria possível trabalhar com capítulos que não fossem iniciais sem afetar o entendimento do leitor/tradutor. Assim sendo, escolhemos os capítulos 6 e 7 por trazerem elementos culturais relevantes e pertinentes à época em que foram escritos.

Podemos destacar alguns trechos imbuídos de elementos culturais presentes na obra e que teriam sua apresentação e elucidação feitas pelo professor em sala de aula. Inicialmente, temos o capítulo 6 intitulado Pig and Pepper no qual Alice adentra a cozinha de uma casa onde encontra a Duquesa segurando um bebê e uma cozinheira mexendo um caldeirão enorme que parecia ser de sopa:

\begin{tabular}{|c|c|}
\hline $\begin{array}{l}\text { Edição inglesa de } 1995 \text { da } \\
\text { Gramercy Books. }\end{array}$ & $\begin{array}{l}\text { Tradução de Nicolau Sevcenko } \\
\text { pela editora Scipione. }\end{array}$ \\
\hline $\begin{array}{l}\text { 1. "(...) the Duchess was sitting } \\
\text { on a three-legged stool in the middle, } \\
\text { nursing a baby: the cook was leaning } \\
\text { over the fire, stirring a large cauldron } \\
\text { which seemed to be full of soup." } \\
\text { (CARROLL: } 36) \text {. }\end{array}$ & $\begin{array}{l}1 . \text { “(...) A duquesa estava } \\
\text { sentada bem no meio, num banquinho de } \\
\text { três pés, cuidando de um bebê. A } \\
\text { cozinheira trabalhava no fogão, } \\
\text { mexendo um enorme caldeirão, que } \\
\text { parecia estar cheio de sopa” (CARROLL: } \\
\text { 69). }\end{array}$ \\
\hline
\end{tabular}
destacado acima. No presente capítulo, nada é mencionado sobre a aparência da Duquesa, mas, no capítulo 9 sabemos que a Duquesa é de aparência 
PONTES, V. O; LIMA, N. S. A.; NUNES, S. L. A. - A atividade tadutória de obras de literatura infantil aplicada ao ensino de língua estrangeira

horrenda e por isso Alice tenta manter distância dela. Há especulações que afirmam que a personagem seria a representação da duquesa Margaret da Caríntia e do Tirol que tem fama de ser a mulher mais feia da história, como afirma Gardner (2002: 57) em suas notas informativas. Aqui, o professor pode perguntar se, no Brasil ou em outras partes do mundo, há figuras históricas e/ou políticas que se destacaram por semelhante característica ou por características desagradáveis, como a pouca higiene dos europeus no início da colonização brasileira, trabalhando assim em campos interdisciplinares que a tradução pode permear.

Outro ponto em destaque seria referente aos hábitos culinários da época como a sopa com bastante pimenta que está sendo feita pela cozinheira e faz Alice espirrar:

\begin{tabular}{|c|c|}
\hline $\begin{array}{c}\text { Edição inglesa de } 1995 \text { da } \\
\text { Gramercy Books. }\end{array}$ & $\begin{array}{l}\text { Tradução de Nicolau Sevcenko } \\
\text { pela editora Scipione. }\end{array}$ \\
\hline $\begin{array}{c}\text { 2. "There's certainly too much } \\
\text { pepper in that soup!" (CARROLL: 37). }\end{array}$ & $\begin{array}{l}\text { 2. "Deve haver pimenta demais } \\
\text { naquela sopa, com certeza!” (CARROLL: } \\
\text { 69). }\end{array}$ \\
\hline
\end{tabular}

Há aqui referência a um costume entre as classes com baixo poder aquisitivo da Inglaterra vitoriana de pôr pimenta demais na sopa para disfarçar o gosto de carne e verdura estragados, já que não tinham dinheiro suficiente para comprar produtos frescos. É possível, aqui, trabalhar novamente com a interdisciplinaridade, tornando-se relevante mencionar e caracterizar o período histórico em que a obra foi escrita. 0 professor poderia também questionar se há algum costume culinário semelhante no Brasil, trabalhando, dessa forma, em cima da tradução intercultural, comparando culturas distintas para uma possível quebra de barreiras e maior aproximação, à luz das teorias de Hinojosa \& Lima (2007).

Mais adiante ainda, na mesma página, nos deparamos com uma conversa entre Alice e a Duquesa em que a menina pergunta o porquê de seu gato sorrir tanto e essa explica apenas que é por ele ser um gato de Cheshire: 
PONTES, V. O; LIMA, N. S. A.; NUNES, S. L. A. - A atividade tadutória de obras de literatura infantil aplicada ao ensino de língua estrangeira

\begin{tabular}{|l|l|}
\hline $\begin{array}{c}\text { Edição inglesa de } 1995 \text { da } \\
\text { Gramercy Books. }\end{array}$ & $\begin{array}{l}\text { Tradução de Nicolau Sevcenko } \\
\text { pela editora Scipione. }\end{array}$ \\
\hline $\begin{array}{c}\text { 3. "Please would you tell me, (...) } \\
\text { why your cat grins like that?" (CARROLL: }\end{array}$ & $\begin{array}{l}\text { 3. "Por favor, a senhora poderia } \\
\text { me dizer por que seu gato sorri desse } \\
\text { jeito?" (CARROLL: 70). }\end{array}$ \\
\hline
\end{tabular}

Segundo Gardner (2002: 58), Carroll utiliza aqui uma expressão muito recorrente em sua época "sorrir como um gato de Cheshire", mas não se sabe ao certo como ela surgiu. Há duas teorias principais sobre o assunto, uma que afirma que a expressão surgira por conta de uma pintura feita por um artista da região de Cheshire, onde o escritor nasceu, em que os leões apareciam sorrindo na tabuleta. A outra seria porque os queijos produzidos na região eram moldados na forma de um gato sorrindo. É possível lançar a pergunta acerca de outras narrativas literárias que tenham felinos como personagens importantes e que simbolismos eles carregam, ampliando, desta forma, o conhecimento literário dos alunos e instigando-os a fazer novas leituras, além de abrir um leque para que novas atividades tradutórias sejam trabalhadas utilizando textos literários.

Mais à frente, encontramos Alice já fora da casa dialogando com o Gato de Cheshire, pedindo direções para chegar a algum lugar:

\begin{tabular}{|l|l|}
\hline $\begin{array}{l}\text { Edição inglesa de } 1995 \text { da } \\
\text { Gramercy Books. }\end{array}$ & $\begin{array}{l}\text { Tradução de Nicolau Sevcenko } \\
\text { pela editora Scipione. }\end{array}$ \\
\hline $\begin{array}{l}\text { 4. "In that direction (...) lives a } \\
\text { Hatter: and in that direction (...) lives a a } \\
\text { March Hare. Visit either you like: they're } \\
\text { both mad." (CARROLL: 40). }\end{array}$ & $\begin{array}{l}\text { Chapeleiro e naquela direçãa (...) vive ume } \\
\text { uma Lebre Aloprada. Visite qualquer um } \\
\text { deles, tanto faz. Ambos são loucos" } \\
\text { (CARROLL: 75). }\end{array}$ \\
\hline
\end{tabular}

Outras expressões que também eram bastante usadas no tempo em que Lewis Carroll escreveu o livro eram: "louco como um chapeleiro" e "louco como uma lebre de março". Naquela época, era comum o uso do elemento químico mercúrio para preparar o feltro dos chapéus e, consequentemente, muitos chapeleiros tinham os movimentos afetados, a fala confusa e os olhos vermelhos por conta do envenenamento. Já em relação às lebres, dois 
PONTES, V. O; LIMA, N. S. A.; NUNES, S. L. A. - A atividade tadutória de obras de literatura infantil aplicada ao ensino de língua estrangeira

cientistas britânicos observaram que o comportamento das lebres durante o período do cio em março é anormal, confirmando a crença popular de que elas enlouqueciam durante esse período. Mais uma vez, a interdisciplinaridade se faz presente tornando possível se trabalhar com temas ligados à biologia e química.

Chegando ao capítulo 7, intitulado $A$ Mad Tea-Party, a menina chega a uma casa e se depara com uma mesa posta ao ar livre onde estão o Chapeleiro Maluco, a Lebre de Março e uma Marmota:

\begin{tabular}{|c|c|}
\hline $\begin{array}{l}\text { inglesa de } 1995 \text { da } \\
\text { oks. }\end{array}$ & $\begin{array}{l}\text { ução de } \mathrm{Ni} \\
\text { Scipione. }\end{array}$ \\
\hline $\begin{array}{l}\text { 5. "There was a table set out } \\
\text { a tree in front of the house, and } \\
\text { larch Hare and the Hatter were }\end{array}$ & $\begin{array}{l}\text { 5. "Havia uma mesa posta, } \\
\text { árvore, em frente à casa ond }\end{array}$ \\
\hline
\end{tabular}

Seria bastante aceitável que se pensasse que Carroll escreveu o capítulo da festa do chá se referindo ao costume dos ingleses de tomar o popular chá das cinco, mas, em suas notas, Garner (2000: 72) revela que a verdade é que o livro foi escrito antes que isso se tornasse costume no país e ele estava apenas se referindo ao hábito que a família de Alice Liddell tinha de servir o chá coincidindo com o jantar das crianças. 0 costume inglês de se tomar chá ao fim da tarde é de conhecimento geral, havendo, assim, a diminuição do filtro afetivo (BALBONI 2011: 4) e uma maior aceitação por parte do aluno devido à aproximação das culturas distintas, como afirmam Hinojosa e Lima (2007: 4).

O dormouse da Inglaterra foi substituído em algumas versões brasileiras por um caxinguelê que é um pequeno roedor que se assemelha a um esquilo e tem seu nome vindo da palavra latina dormire, dormir. Sabe-se que esse animal tem o costume de hibernar no inverno e por isso ele está sempre letárgico na narrativa. Durante a época vitoriana, era costume as crianças terem dormice como animais de estimação e manterem bules de chá com capim ou feno para alimentá-los (GARDNER 2002: 75). Vemos aqui a presença 
PONTES, V. O; LIMA, N. S. A.; NUNES, S. L. A. - A atividade tadutória de obras de literatura infantil aplicada ao ensino de língua estrangeira

da tradução intercultural transpondo barreiras e unindo conhecimentos (HINOJOSA \& LIMA 2007: 4), a tradução funcionando como mediadora, pois o tradutor trabalha não somente com a língua, mas também com fatos e informações. O professor tem a possibilidade de trabalhar com pontos interdisciplinares referentes à história, ciências e geografia, além da língua estrangeira.

Como um último destaque dos pontos socioculturais existentes nesses dois capítulos, podemos citar o poço de melaço mencionado na estória contada pela Marmota onde moravam três irmãs.

\begin{tabular}{|c|c|}
\hline $\begin{array}{l}\text { Edição inglesa de } 1995 \text { da } \\
\text { Gramercy Books. }\end{array}$ & $\begin{array}{l}\text { Tradução de Nicolau Sevcenko } \\
\text { pela editora Scipione. }\end{array}$ \\
\hline $\begin{array}{l}\text { 6. "Once upon a time there were } \\
\text { three little sisters (...) and they lived at } \\
\text { the bottom of a well (...) they lived on } \\
\text { treacle (...) so they were (...) very ill" } \\
\text { (CARROLL: 46). }\end{array}$ & $\begin{array}{l}\text { 6. "Era uma vez três irmãzinhas } \\
\text { (...) Elas viviam no fundo de um poço } \\
\text { (...) viviam de melado (...) elas ficaram } \\
\text { muito doentes" (CARROLL: 86-87). }\end{array}$ \\
\hline
\end{tabular}

Alguns moradores de Oxford e de outros lugares do mundo enviaram cartas informando a Martin Gardner, o escritor das notas informativas da edição de 2002 de Alice's Adventures in Wonderland, que existia um poço em Oxford e que treacle era uma palavra utilizada para se referir a compostos medicinais usados para picadas de cobra, venenos e várias doenças. 0 professor pode aproveitar e inserir elementos da cultura regional fazendo comentários e perguntas sobre práticas que utilizem remédios caseiros para cura de moléstias diversas, mais uma vez, à luz das teorias acerca de formação de identidade cultural e quebras de barreiras culturais (HINOJOSA \& LIMA 2007: 4-5).

Eis o que podemos destacar nos capítulos 6 e 7. Muitas outras reflexões se abrem no decorrer da obra literária, como a possibilidade de se trabalhar o nonsense em forma de prosa ou poesia ou até mesmo trabalhar com a sequência de Alice Through the Looking-Glass, pois a riqueza da narrativa possibilita um criativo trabalho envolvendo a atividade tradutória. 
PONTES, V. O; LIMA, N. S. A.; NUNES, S. L. A. - A atividade tadutória de obras de literatura infantil aplicada ao ensino de língua estrangeira

\section{Le Avventure di Pinocchio}

Em 17 de julho de 1881, Le avventure di Pinocchio teve a sua primeira aparição no Giornale dei bambini, em uma publicação em série até 25 de janeiro de 1883, por Carlo Lorenzini, escritor e jornalista passando depois à história com o pseudônimo de Carlo Collodi. É uma obra que apresenta a transposição literária da ideia de infância, da fronteira entre o mundo das crianças e dos adultos.

Pinocchio é uma criança verdadeira e não é de modo algum modelo de virtude, no início, inimigo dos livros e dos professores, inimigo acérrimo das regras escolares e desobediente às ordens do pai, Geppetto. Diante de tais características, podemos perceber que estamos diante de uma obra que, apesar de ter sido escrita no século XIX, quando prevalecia uma ótica pedagógica moralista na literatura para crianças, mostra, de forma intuitiva, um enfoque da literatura infantil que só se generalizaria no século XX (MARQues 2011: 89).

É fácil notar que o personagem desenhado por Collodi é muito diferente da maior parte dos protagonistas das histórias infantis. Pinocchio é, ao seu modo, um "herói" muito particular: não voa, não fica invisível, não é indestrutível, não sai sempre vitorioso das situações, não tem um comportamento sempre elogiável, pelo contrário, é um "herói” duplo, do bom e do mau exemplo. Um texto que agrada públicos dos mais diferentes, rico de fascínio para as gerações de ontem, mas também para aquelas de hoje e para aquelas que ainda virão.

Pinocchio é um bom menino e um herói mau, ao mesmo tempo, o protagonista e $\mathrm{o}$ antagonista, com todas aquelas nuances que podemos facilmente encontrar em cada um de nós. Não é difícil se dar conta que estamos diante de uma obra atual, ou melhor, atualizável, isto é, que pode ser retomada ou adaptada segundo as exigências e a época. 
PONTES, V. O; LIMA, N. S. A.; NUNES, S. L. A. - A atividade tadutória de obras de literatura infantil aplicada ao ensino de língua estrangeira

A força inovadora da obra talvez seja por se tratar de um romance inserido no final do século XVIII, momento no qual se via a Itália, do ponto de vista das produções infantis, em considerável atraso em comparação aos outros países europeus, por conta da tardia unidade nacional, que aconteceu somente em 17 de março de 1861.

\subsection{Atividade tradutória utilizando Le Avventure di Pinocchio}

Seria impossível trabalhar a tradução de toda a obra literária, por isso, a sugestão para essa atividade com os alunos de língua italiana será a tradução dos capítulos iniciais da obra, os capítulos I e II, por encontrarmos, nesses capítulos iniciais, aspectos interessantes sobre a cultura italiana do século XIX que podem gerar uma enriquecedora discussão durante e após a atividade tradutória.

Os dois primeiros capítulos da obra serão entregues aos alunos que, em grupos de 3 ou 4, deverão fazer a tradução para o português. Utilizaremos essa postura a fim de apresentar a tradução como um desafio entre o estudante e o texto (BALBONI 2011: 17); o aluno exercitará um papel ativo no processo tradutório, ao passo que o professor participará como um mediador e não um juiz -, orientando, explicando eventuais dúvidas dos alunos, incentivando-os no desenvolvimento da atividade e em todo conjunto de procedimentos necessários para realizá-la.

Quadro 2 - Proposta de atividade 2

\begin{tabular}{|c|c|}
\hline Autor & Simone Lopes de Almeida Nunes \\
\hline Tipo de atividade & \multicolumn{1}{|c|}{ Tradução de texto literário (literatura infantil) } \\
\hline Objetivos & $\begin{array}{l}\text { Perceber as diferenças linguísticas entre a } \\
\text { linguísticos }\end{array}$ \\
$\begin{array}{l}\text { língua italiana do século XIX e a língua italiana } \\
\text { contemporânea, especificamente no que se refere à } \\
\text { oralidade. }\end{array}$ \\
\hline Objetivos cognitivos & Desenvolver a habilidade lexical a partir de \\
\hline
\end{tabular}


PONTES, V. O; LIMA, N. S. A.; NUNES, S. L. A. - A atividade tadutória de obras de literatura infantil aplicada ao ensino de língua estrangeira

\begin{tabular}{|c|c|}
\hline & $\begin{array}{l}\text { uma obra de literatura infantil permeada pela } \\
\text { oralidade e o uso de apelidos, partes do corpo e } \\
\text { comida. }\end{array}$ \\
\hline $\begin{array}{l}\text { Objetivos } \\
\text { relacionais }\end{array}$ & $\begin{array}{l}\text { Desenvolver a capacidade de negociação e de } \\
\text { decisão compartilhada (a atividade desenvolvida em } \\
\text { grupos). }\end{array}$ \\
\hline Nível linguístico & C1 ou C2 \\
\hline Tipo de língua & Segunda língua ou L2 \\
\hline $\begin{array}{ll} & \text { Atividade adaptada } \\
\text { a... } & \end{array}$ & Estudantes universitários \\
\hline $\begin{array}{l}\text { Organização } \mathrm{da} \\
\text { atividade }\end{array}$ & Em grupo. \\
\hline $\begin{array}{l}\text { Quando utilizar a } \\
\text { atividade }\end{array}$ & $\begin{array}{l}\text { Quando for oportuno. Pode ser muito útil } \\
\text { durante um laboratório de tradução para que se } \\
\text { compreenda a importância dos elementos culturais no } \\
\text { estudo da língua italiana. }\end{array}$ \\
\hline Duração & Duas aulas de $1 \mathrm{~h}$ e $30 \mathrm{~min}$ \\
\hline $\begin{array}{l}\text { Materiais } \\
\text { necessários }\end{array}$ & Livro, dicionário, caderno e caneta. \\
\hline $\begin{array}{l}\text { Preparação } \\
\text { material }\end{array}$ & $\begin{array}{l}\text { Aquisição da obra literária ou reprodução dos } \\
\text { capítulos a serem utilizados na atividade. }\end{array}$ \\
\hline $\begin{array}{l}\text { Descrição } \\
\text { atividade }\end{array}$ & $\begin{array}{l}\text { 1. O professor separa a turma em } 4 \text { grupos com } \\
3 \text { ou } 4 \text { integrantes cada. } \\
\text { 2. Em seguida, apresenta a proposta de } \\
\text { atividade tradutória que será realizada, fala um pouco } \\
\text { sobre a relevância da obra literária escolhida e, } \\
\text { posteriormente, solicita que cada grupo inicie a } \\
\text { tradução dos capítulos } 1 \text { e } 2 \text { da obra Le avventure di } \\
\text { Pinocchio. A atividade tradutória será iniciada em sala, } \\
\text { com o auxílio do professor nesse primeiro momento, e } \\
\text { finalizada em casa. } \\
\text { 3. Na sala de aula, o professor ficará } \\
\text { observando e conduzindo a atividade, auxiliando em } \\
\text { eventuais dúvidas dos alunos. } \\
\quad 4 \text {. Na aula seguinte, uma vez que todos os } \\
\text { grupos tenham finalizado as suas traduções, } \\
\text { iniciaremos a discussão sobre o que mais gerou } \\
\text { dificuldade no processo tradutório ou, até mesmo, se } \\
\text { gerou alguma dificuldade. } \\
5 \text {. Ao fim das apresentações, o professor } \\
\text { elucida os elementos socioculturais e políticos } \\
\text { existentes ali, com a intenção de levar os alunos a } \\
\text { refletirem que o processo tradutório não se restringe } \\
\text { aos elementos linguísticos, mas também aos culturais. }\end{array}$ \\
\hline Outras sugestões & $\begin{array}{l}\text { Seria de grande valia se o professor levasse } \\
\text { para sala de aula uma ou mais versões da obra } \\
\text { traduzida para o português para apresentar aos alunos } \\
\text { como é possível se fazer várias interpretações e }\end{array}$ \\
\hline
\end{tabular}


PONTES, V. O; LIMA, N. S. A.; NUNES, S. L. A. - A atividade tadutória de obras de literatura infantil aplicada ao ensino de língua estrangeira

\begin{tabular}{|l|l|}
\hline & $\begin{array}{l}\text { traduções a partir de um único texto e mostrando que } \\
\text { ele não está ali como juiz para julgar se a tradução foi } \\
\text { feita de forma correta ou não, mas como mediador da } \\
\text { atividade. }\end{array}$ \\
\hline
\end{tabular}

Depois de finalizadas, as traduções serão recolhidas pelo professor que as colocará lado a lado, em uma tabela organizada por ele, para uma posterior discussão dos elementos culturais. Como a nossa atividade é uma proposta, iremos destacar nos dois capítulos alguns trechos do original que possibilitem uma reflexão acerca dos elementos culturais na língua estrangeira para discussão em negrito, sem a tradução. Vale ressaltar, que a interculturalidade no uso da tradução em sala de aula, tem o objetivo de levar o aluno à reflexão de que tal atividade não se restringe a elementos linguísticos, mas vai bem mais além.

(...) somente com a tradução os alunos podem se dar conta de quanta cultura, de quanta visão de mundo, de quantos valores estão engastados em cada palavra. Se o aluno descobrir a infinita complexidade das línguas, o modo mágico com que cada língua se impregna do espírito de um povo e com o qual resiste, luta, se debate para não ser traduzida, e se o aluno, sentindo-se pouco capaz, se recusar a traduzir para não trair, o sucesso da tradução como técnica didática será total. (BALBONI 2011: 1).

Posterior à atividade de tradução que será iniciada em sala e finalizada em casa, os alunos irão apresentar os pontos que geraram mais dificuldades durante esse processo e os pontos positivos e negativos dessa prática. Em seguida, destacaremos partes da obra literária que gerarão uma análise dos elementos socioculturais de maior relevância para compreender a cultura italiana do século XIX e um possível diálogo com a contemporaneidade, além de refletir sobre a própria cultura. Os trechos selecionados para discussão são os seguintes: 
PONTES, V. O; LIMA, N. S. A.; NUNES, S. L. A. - A atividade tadutória de obras de literatura infantil aplicada ao ensino de língua estrangeira

\begin{tabular}{|c|c|}
\hline $\begin{array}{l}\text { Edição italiana da edi } \\
\text { Itrinelli }\end{array}$ & $\mathrm{T}$ \\
\hline $\begin{array}{l}1 . \quad \text { “(..) il quale ar } \\
\text { nome mastr'Antonio se non che } t \\
\text { lo chiamavano maestro Cili } \\
\text { (...)". (CoLLODI:19-20) }\end{array}$ & $\begin{array}{l}\text { 1. “(...) que tinh } \\
\text { Antônio, mas que to } \\
\text { mestre Cereja (...)". } \\
\text { (COLLODI: 3) }\end{array}$ \\
\hline
\end{tabular}

O início da narrativa collodiana apresenta o mestre Cereja, o primeiro a notar a estranha lenha falante e, posteriormente, levar para o velho Geppetto. Na frase apresentada, temos dois termos em destaque: o primeiro, o título maestro (mestre) que, na época, era um título designado aos mais velhos (TEMPESTI ${ }^{\text {i4 }}$ 2010:20) e o segundo termo em destaque, Ciliegia (Cereja), leva a reflexão do uso de apelidos, gênero presente na mais vasta cultura falada, que graças a registros como o dessa narrativa, podemos tomar conhecimento. Tempesti, nos comentários da obra Pinocchio, explica que o apelido é a identificação da personalidade, das suas tendências e preferências; é um resumo da sua história, daquilo que se sabe e se diz sobre a pessoa. Nesse momento, o professor pode até fazer um momento de conversação com os estudantes para saber se alguém tem algum apelido e qual a relação com a própria história. A relação intercultural pode e deve ser encorajada pelo professor de LE, pois "a questão de que a educação intercultural aproxima indivíduos de culturas distintas é de suma importância" (HINOJOSA; LIMA 2007: 4), encorajando, também, o desenvolvimento de habilidades inter-relacionadas. A relação entre o aspecto histórico-cultural com hábitos sociais contemporâneos pode trazer uma motivadora discussão, além de um excelente exercício da oralidade em LE.

3 Utilizamos uma obra traduzida por Marina Colasanti pela Companhia das Letrinhas, disponível no link: https://cld.pt/dl/download/0608bc89-5793-45fa-979d-151a556f8305/AsAventuras-de-Pinoquio.pdf

${ }^{4}$ Fernando Tempesti é um especialista em Collodi e faz o comentário da obra literária Pinocchio utilizada na nossa proposta de atividade. 
PONTES, V. O; LIMA, N. S. A.; NunES, S. L. A. - A atividade tadutória de obras de literatura infantil aplicada ao ensino de língua estrangeira

Ainda no início da obra, Mestre Cereja, executando o seu ofício habitual, pega um pedaço de madeira e, ao ameaçar dar a primeira martelada, escuta uma vozinha fina que parte da madeira, mas ao constatar não haver ninguém no estabelecimento nem nas proximidades de sua casa, chega a seguinte conclusão:

\begin{tabular}{|c|c|}
\hline $\begin{array}{llll}\text { Edição italiana da editora } \\
\text { Feltrinelli }\end{array}$ & Tradução nossa \\
\hline $\begin{array}{l}\text { 2. "- Ho capito; - disse allora } \\
\text { ridendo e grattandosi la parrucca - si } \\
\text { vede che quella vocina me la sono } \\
\text { figurata io. Rimettiamoci a lavorare. } \\
\text {-" (CollodI: } 21 \text { ) }\end{array}$ & $\begin{array}{l}\text { 2. "- Entendi - disse então rindo. - } \\
\text { Vai ver que fui eu mesmo que inventei } \\
\text { aquela vozinha." } \\
\text { (COLLODI: 3) }\end{array}$ \\
\hline
\end{tabular}

A peruca, hoje tratada com certo menosprezo - exemplo disso é o fato da própria tradutora suprimir tal elemento na sua tradução para o português , já foi um acessório sinônimo de elegância e prestígio. Tempesti revela que Collodi era um homem calvo, porém vivia a sua calvície com certo sofrimento. Fato é que, naquela época (1880) a peruca representa não somente um símbolo pessoal, mas também de mentalidade, de costume. O seu uso é marcadamente reflexo do século anterior à obra, reis como Luís XIII e Luís XIV da França eram adeptos do acessório. Com a Revolução Francesa, ocorrida em 1789, o uso das perucas entra em declínio. É importante ressaltar para os alunos que as tradições inventadas, na era em que sucederam às revoluções Francesa e Industrial, preencheram uma lacuna permanente na vida pública dos cidadãos (HOBSBAWN 1984:11). O professor pode aproveitar o tema desenvolvido na atividade tradutória para instigar os alunos a pesquisar sobre costumes antigos que não influenciam mais a sociedade contemporânea, ou, ainda, sobre as mudanças de sentido dos objetos antigos, e as apresentações podem, inclusive, servir para uma avaliação oral. A interculturalidade, aqui, integra em uma unidade as diferenças culturais temporais através de uma relação dialógica entre indivíduos (HINOJOSA; LIMA 2007: 1).

Outro elemento cultural aparece quando Mestre Cereja começa a se perguntar se o pedaço de madeira é capaz de ter aprendido a chorar e a se 
PONTES, V. O; LIMA, N. S. A.; NUNES, S. L. A. - A atividade tadutória de obras de literatura infantil aplicada ao ensino de língua estrangeira

lamentar como uma criança. E constata que a madeira serve para ferver uma panela de feijão:

\begin{tabular}{|c|c|}
\hline $\begin{array}{l}\text { Edição italiana da editora } \\
\text { Feltrinelli }\end{array}$ & Tradução nossa $^{5}$ \\
\hline $\begin{array}{l}\text { 3. "c'è da far bollire una } \\
\text { pentola di fagioli" (COLLODI :22). }\end{array}$ & $\begin{array}{l}\text { 3. "serve para cozinhar uma panela } \\
\text { de feijão" }\end{array}$ \\
\hline
\end{tabular}

0 professor pode lançar a seguinte questão para os alunos: por que o autor escolhe o feijão e não outro alimento qualquer em sua narrativa? Desse questionamento, o professor pode introduzir a realidade italiana pós-unificada e os problemas sociais e econômicos sofridos pelos italianos na passagem do século XIX para o século XX, uma atividade paralela que pode ser feita através de slides, vídeos ou textos que tratem da temática. Particularmente, o feijão, citado na obra, era um alimento fundamental na mesa do povo florentino. Vale ressaltar que Florença era a cidade natal de Collodi, por isso a referência de uma realidade bastante conhecida pelo autor. De fato, o feijão fazia parte da cultura alimentar toscana - não somente toscana obviamente - como um alimento de uso comum e também desejado. A dura realidade econômica da Itália pós-unificada aparecerá em outro momento da narrativa collodiana, quando o feijão aparecerá pintado na parede da casa de Geppetto, simbologia de um alimento desejado, mas de escasso consumo. Muitas vezes, a história do país, no ensino de LE, não encontra o seu espaço, dessa forma, a atividade tradutória pode propor uma nova perspectiva para a introdução de elementos históricos da língua estudada, pois:

(...) uma língua não existe apenas para veicular enunciados, mas, sim, e sobretudo, para revelar universos, princípios, forças, e para revelar, enfim, diversidades, adversidades, maravilhas, a história em geral. 0 ensino de LE deve, assim, estar em sintonia com essa concepção, para que a prática escolar não acentue o fosso, já

\footnotetext{
${ }^{5}$ A tradução de Marina Colasanti omitiu esse trecho, portanto, apresentamos uma sugestão de tradução nossa.
} 
PONTES, V. O; LIMA, N. S. A.; NUNES, S. L. A. - A atividade tadutória de obras de literatura infantil aplicada ao ensino de língua estrangeira

existente, entre o processo educacional, como um todo, e o ensino de LE (LAMEIRAS 2008: 31).

Passando para o segundo capítulo, Mestre Cereja leva o pedaço de madeira ao velho Geppetto que é apresentado dessa forma:

\begin{tabular}{|c|c|}
\hline $\begin{array}{l}\text { Edição italiana da editora } \\
\text { Feltrinelli }\end{array}$ & $\begin{array}{l}\text { Tradução de Marina Colasanti pela } \\
\text { editora Companhia das Letrinhas }\end{array}$ \\
\hline $\begin{array}{l}\text { 4. “(...) i ragazzi del vicinato, } \\
\text { quando lo volevano far montare su } \\
\text { tutte le furie, lo chiamavano col } \\
\text { soprannome di Polendina (...)" } \\
\text { (ColLoDI: } 24) \text {. }\end{array}$ & $\begin{array}{l}\text { 4. “(...) para irritá-lo, os meninos da } \\
\text { vizinhança o chamavam de Polentinha (...)” } \\
\text { (COLLODI: 3) }\end{array}$ \\
\hline
\end{tabular}

Mais uma vez o uso de apelido apresenta-se como uso exclusivo da língua falada. 0 apelido designava-se um fato pacífico, segundo Tempesti, quando era herdado, não mais que uma geração, e vinham a tornar-se sobrenome, ou seja, seguiam a lei histórica de formação de sobrenomes. Podemos observar, pelo trecho acima apresentado, que esse fato não se verifica com Geppetto, que se enfurece com o apelido lançado pelos meninos da vizinhança, Polentinha. Tal apelido refere-se somente à cor amarelada da peruca de Geppetto. Nesse momento da atividade, o professor pode lançar, ou perguntar aos alunos, uma lista de apelidos que podem trazer transtornos para quem os recebe. Seria o caso de, talvez, focar em aspectos que correspondessem ao corpo humano, introduzindo, dessa forma, esse vocabulário para os alunos, mas não de forma solta, vazia, fazendo sempre a ligação apelido-corpo humano. Tal proposta desmistifica o ensino de LE como "uma vitrine de palavras soltas" (LAMEIRAS 2008: 34), redireciona a prática pedagógica ampliando os horizontes do aluno de forma contextualizada.

Finalmente, mestre Cereja presenteia Geppetto com o pedaço de madeira, mas o pedaço de madeira dá uma sacudidela e vai bater nas canelas do pobre Geppetto que reclama ao amigo: 
PONTES, V. O; LIMA, N. S. A.; NUNES, S. L. A. - A atividade tadutória de obras de literatura infantil aplicada ao ensino de língua estrangeira

\begin{tabular}{|c|c|}
\hline $\begin{array}{llll}\text { Edição } & \text { italiana da editc } \\
\text { Feltrinelli }\end{array}$ & $\begin{array}{l}\text { ão de Marina Cola } \\
\text { anhia das Letrinhas }\end{array}$ \\
\hline $\begin{array}{l}\text { 5. “- Ah! gli è con questo bel } \\
\text { garbo, mastr'Antonio, che voi } \\
\text { regalate a vostra roba?" (CoLLODI: } \\
\text { 27). }\end{array}$ & $\begin{array}{l}\text { 5. - Ah! É com essa delicadeza, } \\
\text { mestre Antônio, que o senhor dá um } \\
\text { presente?" (COLLODI: } 5)\end{array}$ \\
\hline
\end{tabular}

Os alunos irão perceber a ironia na fala de Geppetto, visto que, desde sempre, o modo de se presentear alguém é uma gentileza imbuída de refinamento e delicadeza. Não se presenteia ninguém de forma agressiva. Essa frase pode ser a introdução para que os alunos pesquisem outros exemplos de ironia em outros textos, como o jornalístico, dessa forma, o professor pode partir do texto literário para o não literário, apresentando outros gêneros textuais. 0 professor pode, ainda, explorar as figuras de linguagem dentro da própria obra collodiana, com outros exemplos que o próprio docente irá destacar e apresentar aos alunos, explicando cada figura e o efeito produzido.

Abre-se, então, um mundo de possibilidades e a continuidade da obra permite uma maior exploração não somente de outros elementos culturais, mas também, através da atividade tradutória, o aluno pode ser estimulado a refletir sobre elementos fantásticos, políticos, infantis, didático-pedagógicos, enfim, as possibilidades para o uso de atividade utilizando a tradução são ricas e totalmente aplicáveis. Caberia, ainda, a proposta de uma apresentação teatral no final da atividade de tradução comentada. 0 professor pode apresentar uma breve exploração das diversas traduções feitas da obra para outros meios como teatro, cinema, quadrinhos, literaturas das mais variadas.

Observamos que a língua não veicula apenas enunciados, mas revela múltiplas interações que surgem ao vincularmos a tradução ao ensino de LE e é nessa coexistência que se pode descobrir a riqueza das relações entre diferentes línguas e culturas. 
PONTES, V. O; LIMA, N. S. A.; NUNES, S. L. A. - A atividade tadutória de obras de literatura infantil aplicada ao ensino de língua estrangeira

\section{Considerações finais}

Acreditamos que o elemento cultural na atividade tradutória pode servir de ponte, à medida que o aluno se abre para o mundo do outro, e inversamente reflete a sua própria identidade cultural. Lameiras (2006) reconhece a importância que a relação entre cultura e ensino de línguas pode exercer diante de uma política de ensino de línguas. Diante dessa relação, para a autora, a cultura deixa de ser um "adorno" e passa a ser um "patrimônio", ou seja, um bem de todos, independentemente da classe, da nacionalidade, da língua; que vem para unificar.

O uso da tradução em sala de aula será uma ferramenta fundamental nessa relação cultura e ensino de línguas. A tradução exerce um novo papel na era do pós-método, ao adquirir cada vez mais espaço nas discussões acadêmicas do seu uso como estratégia significativa no ensino de LE. Com as atividades apresentadas no presente artigo percebemos que diversas discussões, reflexões e exercícios orais e escritos podem ser desenvolvidos através da tradução e o texto literário pode ser um importante aliado nessa perspectiva. Apresentado, em livros didáticos, muitas vezes para análises aspectuais, o texto literário pode contribuir de forma criativa para a atividade tradutória; evidentemente, a sua escolha deve ser pensada de forma a estimular os alunos e que o mesmo apresente elementos que contribuam com a prática pedagógica e a aprendizagem em LE.

Diante de uma área tão incipiente em propostas didáticas que incluam a tradução no ensino de línguas, propomos uma reflexão sobre Tradução e Ensino com atividades práticas e possíveis, e assim evitamos a concentração na discussão da utilização da tradução no ensino de língua estrangeira. As duas atividades propostas sinalizam que é possível apresentar ao aluno que o enunciado da língua não é o único elemento a ser estimulado na atividade de tradução: os seus elementos culturais apresentam-se como um rico patrimônio 
PONTES, V. O; LIMA, N. S. A.; NUNES, S. L. A. - A atividade tadutória de obras de literatura infantil aplicada ao ensino de língua estrangeira

que alarga o conhecimento do próprio e do estrangeiro. Além disso, a atividade de tradução faz do aluno um participante ativo e autônomo no processo de ensino-aprendizagem da LE, capaz de ampliar o seu horizonte, graças a um redirecionamento da prática pedagógica.

\section{Referências bibliográficas}

Branco, S. O. Teorias da Tradução e o ensino de língua estrangeira. Horizontes de Linguística Apliacada, v. 8, n. 2, pp. 185-199, 2009.

BALBONI, P. E. A tradução no ensino de línguas: história de uma difamação. Revista In-traduções, ed. 4. Trad. Maria Teresa Arrigoni. Rev. Noêmia Soares e Sérgio Romanelli. Universidade Federal de Santa Catarina, 2011.

CARROLL, L. Alice's Adventure in Wonderland. New York: Gramercy Books, 1995.

Alice: edição comentada Notas e comentários de Martin Gardner. Tradução de Maria Luiza X. de A. Borges. Rio de Janeiro: Jorge Zahar, 2002.

. Alice no País das Maravilhas. Trad. Nicolau Sevcenko. São Paulo: Scipione, 1995

Collodi, C. Pinocchio. Introdução e comentário crítico de Fernando Tempesti. Firenze: Felice Paggi Editore, 1883.

Even-Zohar, I. Polysystem studies. Poetics today: international journal for theory and analysis of literature and communication, v. 11, n. 1, 1990. Disponível em: www.tau.ac.il/ itamarez/works/books/ez-pss1990.pdf. Acesso em: 15 out. 2014.

HiNojosA, F. R.; LIMA, R. A tradução como estratégia de interculturalidade no ensino de língua estrangeira. Bocc. Biblioteca Online de Ciências da Comunicação, 2007, v. 1, pp. 1-10. Disponível em: www.bocc.ubi.pt/pag/lima-hinojosa-tradução-estrategiainterculturalidade.pdf. Acesso em: 15 out. 2014. 
PONTES, V. O; LIMA, N. S. A.; NUNES, S. L. A. - A atividade tadutória de obras de literatura infantil aplicada ao ensino de língua estrangeira

HobsBawn, E. Introdução: A invenção das Tradições. In: HobsBaWn, E. \& RANGER, T. (Orgs.). A invenção das tradições. Rio de Janeiro: Paz e Terra, 1984: 9-23.

KramsCH, C. Context and culture in language teaching. Oxford: Oxford University Press, 1993.

Krashen, S. D. Principles and Practice in Second Language Acquisition. Prentice-Hall International, 1987.

. Second Language Acquisition and Second Language Learning. Prentice-Hall International, 1988.

Lameiras, M. S. T. B. Ensino de língua x cultura: em busca de um aprendiz artesão, autônomo e cidadão. In: TAVARES, R. (Org.). Língua, Cultura e Ensino. Maceió: EDUFAL, 2008.

Leite, S. U. O que a tartaruga disse a Lewis Carroll. In: Carroll, L. As aventuras de Alice no país das maravilhas através do espelho e que Alice encontrou lá. 3 ed. São Paulo: Summus, 1980: 7-36.

LuCINDO, E. S. Tradução e ensino de línguas estrangeiras. Sicentia Traductionis, vol. 0, n. 3, nov. 2006. Disponível em: www.scientiatraductionis.ufsc.br/edicoes $3 . \mathrm{html}$

MARQUES, V. dos S. A variação de léxico nas traduções modernas de Pinóquio. Cadernos de Literatura em Tradução, n. 12, pp. 87-102, 2011.

RomAnelLI, S. 0 uso da tradução no ensino-aprendizagem das línguas estrangeiras. Revista Horizontes de Linguística Aplicada, v. 8, n. 2, pp. 200219, 2009.

SCHLEIERMACHER, F. Sobre os diferentes métodos de tradução. Tradução de Margarete von Mühlen Poll. In: Heidermann, W. (Org.). Clássicos da teoria da tradução - volume 1: alemão português. Florianópolis: UFSC, 2010: 27-85.

SILVA, T. T. da (org.). Alienígenas na sala de aula. Petrópolis/RJ: Vozes, 1995.

VenUtI, L. Escândalos da Tradução. Trad. Laureano Pelegrin, Lucinéia Marcelino Villela, Marileide Dias Esqueda, Valéria Bioondo. Bauru, SP: EDUSC, 2002. 